\title{
The Effect of Implementation of 5S on Kaizen and Quality
}

\author{
Eko Yuli Susanto ${ }^{1}$ Niken Sulistyowati ${ }^{2}$ \\ Magister Management Postgraduate Program, Mercu Buana University, Jakarta Indonesia
}

\begin{abstract}
This study aims to analyze the effect of implementation of $5 \mathrm{~S}$ on Quality, the effect of implementing implementation of 5S on Kaizen and the effect of Kaizen on Quality in this case is Out-of-Pit Overburden Crusher dan Conveyor system (OPCC) Coal Mining Industry. Analysis of the effect of Implementation of 5S and Kaizen on site operation area in 2018. By using data collection methods in the form of library studies and questionnaires to 220 respondents. The method of data analysis in this study uses Structural Equation Modeling (SEM). The results showed that implementation of $5 \mathrm{~S}$ had a significant and positive effect on Quality with the strongest relationship of variables explained by the indicators of "Productivity Level" and Kaizen with the strongest relationship of variables explained by the indicator "The scope of internal improvement of the department and or section (group)". And Kaizen has a significant and positive effect on Quality with the strongest relationship of variables explained by the indicator "Identification and classification of material (required and not required)".
\end{abstract}

Keywords: Implementation of 5S, Quality, Kaizen, Coal Mining, Structure Equation Modelling.

DOI: $10.7176 / \mathrm{EJBM} / 12-18-08$

Publication date:June 30th 2020

\section{Introduction}

Competition in the industry is getting harder, all companies engaged in industry strive to produce the highest quality products. In this era of industrialization every organization is required to be able to adapt to uncertainty. Organizations that can adapt will be able to compete and take their roles as winners, including the coal industry. With external pressure on falling commodity prices, companies are also required to carry out optimal and efficient operating performance. Performance improvement is supported by the application of the $5 \mathrm{~S}$ culture that improves the work environment and Kaizen for continuous improvement. Based on previous research, indicating the application of 5S can provide benefits for Organizational efficiency (Arash Ghodrati et al, 2012) and performance improvement (Rojasra, P. M et al, 2013). Likewise with Kaizen, previous research indicates that Kaizen will contribute to improving Quality and Performance (Rajesh Mahto et al, 2017). The object research carried out the implementation of 5S and Kaizen in Mining Industry with objective companies can improve Quality, Cost, Delivery, Morale, Productivity and Environment (QCDMPE) better and provide the best service for customers (Mawih et al, 2019). Based on the phenomena mentioned above, the author is interested in further researching the implementation of $5 \mathrm{~S}$ and Kaizen and their impacts. With this research a theory can be built that can function to explain, predict, and control a symptom, which then respondent results are analysed using AMOS software.

\section{Literatur Review}

Ho (2008) illustrates a new paradigm regarding the formation of a work culture, which starts from how the company performs an efficient attitude and then makes these actions a habit which can further assist top management in determining the company's mission and vision which in turn can form a guiding culture by employees at work. Ho (2008) states that Japanese work culture, often called Kaizen, is an action that reflects the $5 \mathrm{~S}$ work culture and can affect a person's work quality for the better. $5 \mathrm{~S}$ is a series of activities in the workplace in the form of sorting, structuring, cleaning, and habituation activities which are all needed to carry out good work. Osada (2000) determine 5S work culture is a determination to hold Seiri (Sort) at work, Seiton (Set in order), Seiso (Shine), Seiketsu (Standardize), steady conditions and Shitsuke (Sustain) to maintain the habits needed to carry out work well.

Imai (2008) Kaizen or continuous improvement is a continuous process improvement to always improve the quality and productivity of output. This means that in kaizen it is strived towards goals that have been outlined slowly or gradually becoming better but consistently, so that after a certain period of time a large total effect is achieved in terms of the process. To get a quality product, one way to improve quality and productivity using the Kaizen program. Kaizen which means perfecting or becoming more perfect.

According to David Garvin in Fandy Tjiptono (2005) product quality has eight dimensions, namely: 1. Performance, related to the functional aspects of the product. 2. Features (relating to choices and development).3. Reliability, related to the failure rate in using the product. 4. Serviceability, related to the ease and cost of repairs. 5. Conformance, related to the level of conformity of products to specifications that have been predetermined based on customer desires. 6. Durability, related to the durability or lifetime of the product. 7. Aesthetics, relating to the design and packaging of the product. 8. Perceived Quality, that is, the image and reputation of the product and the company's responsibility towards it. 
In this study, based on the background, theoretical basis and previous studies that are relevant and supportive, the authors compile a framework of thinking referring to the schema in Figure 1 below. The model of thinking consists of 3 (three) variables consisting of 5S, Kaizen and Quality.

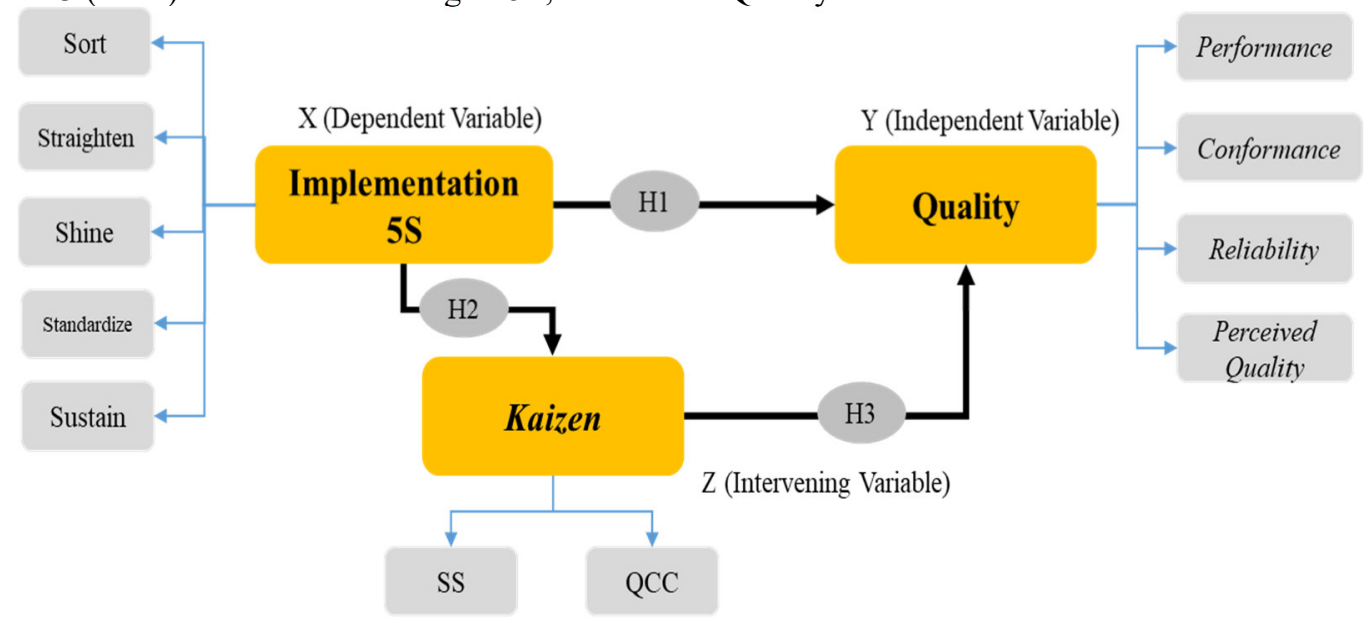

Figure 1. Research Framework

The hypothesis is a temporary answer to the formulation of research problems, therefore the formulation of research problems is usually arranged in the form of question sentences. Based on the theoretical foundation and the phenomena that occur, the researcher formulates the hypothesis as follows:

Hypothesis 1: Implementation 5S has a positive effect on Quality, 5R provides improved performance (Rojasra, P. M et al, 2013) and reduced operating time for engine replacement (Ab Rahman et al, 2010).

Hypothesis 2: Implementation 5S has a positive effect on Kaizen, 5R provides reduced operating time for machine replacement (Ab Rahman et al, 2010) and provides efficiency benefits for organizations (Arash Ghodrati et all, 2012)

Hypothesis 3: Kaizen has a positive effect on Quality, Kaizen will provide a problem solving method (C.P.Carvalho et al, 2017) and can contribute in improving Quality and Performance (Rajesh Mahto et al, 2017)

\section{Research Method}

The research method used in this study is a quantitative statistical method using a survey approach. The survey approach method is research that takes a sample from one population and uses questionnaires as a primary data collection tool. The questionnaire is measured by a semantic differential scale where this scale measures the attitude of respondents consisting of a continuum line from the lowest point 1 to the highest point 10 (Ferdinand, 2014). The study population included employees of PT XYZ at site operation. The data analysis technique used in this study is Structural Equation Modelling (SEM) with AMOS 24 applications. The stages of analysis are through the Confirmatory Factor Analysis, Average Variance Extracted, Construct Reliability, Normality Test, Goodness of Fit Test and Hypothesis Test.

\section{Result And Discussion}

Characteristics of Respondents

The number of respondents in this study were 220 respondents. Data on the characteristics of respondents can be seen in the table below: 
Table 1. Characteristics of Respondents

\begin{tabular}{|l|c|c|}
\hline Characteristic of Respondents & Frequency & Prosentage \\
\hline Gender & 200 & $91 \%$ \\
\hline Male & 20 & $9 \%$ \\
\hline Female & 9 & $4 \%$ \\
\hline Age & 57 & $26 \%$ \\
\hline$<20$ years & 62 & $28 \%$ \\
\hline $20-<25$ years & 53 & $24 \%$ \\
\hline $25-<30$ years & 39 & $18 \%$ \\
\hline $30-<35$ years & \multicolumn{2}{|l|}{} \\
\hline$\geq 35$ years & 82 & $37 \%$ \\
\hline Working Unit & 102 & $46 \%$ \\
\hline Operation & 14 & $6 \%$ \\
\hline Maintenance & 7 & $3 \%$ \\
\hline Procurement \& Logistics & 8 & $4 \%$ \\
\hline HRGA & 3 & $1 \%$ \\
\hline HSE & 4 & $2 \%$ \\
\hline Finance & \multicolumn{2}{|l}{} \\
\hline Business Process Improvement &
\end{tabular}

Source: Results of data processing (2019)

\section{Test Validity and Reliability}

Confirmatory Factor Analysis and Construction Reliability Test

Confirmatory Factor Analysis (CFA) test results show that all indicators of the dimensions and dimensions of the construct obtained probability values at the level of 0.001 and loading estimated values above 0.5 (Haryono, 2017). There are two test methods that can be used, namely construct reliability (CR) and variance extracted (VE), the cut-off value of construct reliability is a minimum of 0.7 while the extracted variance is at least 0.5 (Ghozali, 2016). Results of CFA and Construction Reliability Test can be seen in the table below:

Table 2. CFA \& Construction Reliability Test Implementation of 5S

\begin{tabular}{|c|c|c|c|c|c|c|c|c|c|}
\hline Variable & $\lambda$ & $\begin{array}{c}\mathrm{p}- \\
\text { value }\end{array}$ & $\mathrm{CR}$ & $\begin{array}{c}\text { Variance } \\
\text { Extract }\end{array}$ & Indicator & $\lambda$ & $\begin{array}{c}\mathrm{p}- \\
\text { value }\end{array}$ & $\mathrm{CR}$ & $\begin{array}{c}\text { Variance } \\
\text { Extract }\end{array}$ \\
\hline \multirow{2}{*}{ Sort } & \multirow{2}{*}{0,570} & \multirow{2}{*}{$* * * *$} & \multirow{10}{*}{$\begin{array}{c}0,92 \\
3\end{array}$} & \multirow{10}{*}{0,711} & RR1.1 & 0,827 & $* * * *$ & \multirow{2}{*}{0,706} & \multirow{2}{*}{0,549} \\
\hline & & & & & RR1.2 & 0,644 & $* * * *$ & & \\
\hline \multirow{2}{*}{ Set in order } & \multirow{2}{*}{0,899} & \multirow{2}{*}{$* * * *$} & & & RR2.1 & 0,751 & $* * * *$ & \multirow{2}{*}{0,746} & \multirow{2}{*}{0,595} \\
\hline & & & & & RR2.4 & 0,791 & $* * * *$ & & \\
\hline \multirow{2}{*}{ Shine } & \multirow{2}{*}{0,990} & \multirow{2}{*}{$* * * *$} & & & RR3.1 & 0,812 & $* * * *$ & \multirow{2}{*}{0,747} & \multirow{2}{*}{0,597} \\
\hline & & & & & RR3.3 & 0,731 & $* * * *$ & & \\
\hline \multirow{2}{*}{ Standardize } & \multirow{2}{*}{0,874} & \multirow{2}{*}{$* * * *$} & & & RR4.1 & 0,725 & $* * * *$ & \multirow{2}{*}{0,741} & \multirow{2}{*}{0,589} \\
\hline & & & & & RR4.3 & 0,808 & $* * * *$ & & \\
\hline \multirow{2}{*}{ Sustain } & \multirow{2}{*}{0,823} & \multirow{2}{*}{$* * * *$} & & & RR5.1 & 0,707 & $* * * *$ & \multirow{2}{*}{0,709} & \multirow{2}{*}{0,550} \\
\hline & & & & & RR5.2 & 0,775 & $* * * *$ & & \\
\hline
\end{tabular}

Table 3. CFA \& Construction Reliability Test Kaizen

\begin{tabular}{|c|c|c|c|c|c|c|c|c|c|}
\hline Variable & $\lambda$ & $\begin{array}{c}\text { p- } \\
\text { value }\end{array}$ & $\mathrm{CR}$ & $\begin{array}{c}\text { Variance } \\
\text { Extract }\end{array}$ & Indicator & $\lambda$ & $\begin{array}{c}\text { p- } \\
\text { value }\end{array}$ & $\mathrm{CR}$ & $\begin{array}{c}\text { Variance } \\
\text { Extract }\end{array}$ \\
\hline \multirow{2}{*}{ SS } & \multirow{2}{*}{0,952} & \multirow{2}{*}{$* * * *$} & \multirow{4}{*}{0,966} & \multirow{4}{*}{0,934} & KSS.1 & 0,763 & $* * * *$ & \multirow{2}{*}{0,732} & \multirow{2}{*}{0,578} \\
\hline & & & & & KSS.3 & 0,757 & $* * * *$ & & \\
\hline \multirow{2}{*}{ QCC } & \multirow{2}{*}{0,981} & \multirow{2}{*}{$* * * *$} & & & KQC.1 & 0,842 & $* * * *$ & \multirow{2}{*}{0,719} & \multirow{2}{*}{0,565} \\
\hline & & & & & KQC.3 & 0,649 & $* * * *$ & & \\
\hline
\end{tabular}


Table 4. CFA \& Construction Reliability Test Quality

\begin{tabular}{|c|c|c|c|c|c|c|c|c|c|}
\hline Variable & $\lambda$ & $\begin{array}{l}\mathrm{p}- \\
\text { value }\end{array}$ & $\mathrm{CR}$ & $\begin{array}{l}\text { Variance } \\
\text { Extract }\end{array}$ & Indicator & $\lambda$ & $\begin{array}{l}\mathrm{p}- \\
\text { value }\end{array}$ & CR & $\begin{array}{l}\text { Variance } \\
\text { Extract }\end{array}$ \\
\hline \multirow{2}{*}{ Performance } & \multirow{2}{*}{0,842} & \multirow{2}{*}{$* * * *$} & \multirow{8}{*}{0,888} & \multirow{8}{*}{0,667} & MTA.1 & 0,911 & $* * * *$ & \multirow{2}{*}{0,899} & \multirow{2}{*}{0,817} \\
\hline & & & & & MTA.2 & 0,897 & $* * * *$ & & \\
\hline \multirow{2}{*}{ Conformance } & \multirow{2}{*}{0,745} & \multirow{2}{*}{$* * * *$} & & & MTD.1 & 0,758 & $* * * *$ & \multirow{2}{*}{0,765} & \multirow{2}{*}{0,619} \\
\hline & & & & & MTD.2 & 0,815 & $* * * *$ & & \\
\hline \multirow{2}{*}{ Reliability } & \multirow{2}{*}{0,911} & \multirow{2}{*}{$* * * *$} & & & MTR.1 & 0,839 & $* * * *$ & \multirow{2}{*}{0,841} & \multirow{2}{*}{0,726} \\
\hline & & & & & MTR.2 & 0,865 & $* * * *$ & & \\
\hline \multirow{2}{*}{$\begin{array}{l}\text { Perceived } \\
\text { Quality }\end{array}$} & \multirow{2}{*}{0,757} & \multirow{2}{*}{$* * * *$} & & & MTC.1 & 0,737 & $* * * *$ & \multirow{2}{*}{0,753} & \multirow{2}{*}{0,605} \\
\hline & & & & & MTC. 2 & 0,816 & $* * * *$ & & \\
\hline
\end{tabular}

Source: Results of data processing (2019)

Based on Tables 2, 3 and 4 above, all dimensions and indicators have a probability value (P-Value) of 0.001 $(* * *)$ and a standardized estimate $(\lambda)$ value greater than 0.5 then it is concluded that all dimensions and indicators of the variable is valid. All dimensions and indicators have CR values $>0.7$ and VE values $>0.5$ so that it is concluded that the constructs of dimensions and indicators are valid and reliable.

\section{Test for Assumption of Normality and Outliers}

Multivariate normality analysis on AMOS 24 was performed using the criterion ratio criterion (c.r) of multivariate in kurtosis. If the value of $\mathrm{cr}$ is in the range between \pm 2.58 it indicates that the data is normally distributed multivariate (Haryono, 2017). Normality test results show that the value of c.r. CR skewness and CR kurtosis values for each indicator are in the range of -2.58 and +2.58 so that it can be concluded that the data meet the univariate normality requirements. Otherwise, the multivariate CR value shows the value of 2,464, meaning that the data meets the multivariate normality requirements.

In this study, the number of indicators used was 22 so that at the level of $\mathrm{p} 0.001$ the $\mathrm{X}^{2}$ value of 48.268 was obtained. And the highest Mahalanobis Distance value is 38,821 lower than $\mathrm{X}^{2}$ table (48.268). It means that there is no outlier data.

\section{Goodness of Fit Test}

The complete model of the structural test results and model modification is obtained by Goodness of Fit data as shown in Table 5 below.

Table 5.Goodness of Fit

\begin{tabular}{|c|c|c|c|c|}
\hline Goodness of fit indices & Cut off value & Initial & After Modification & Conclusion \\
\hline $\begin{array}{c}\text { CMIN } \\
\mathrm{X}^{2} \text { Hitung }<\mathrm{X}^{2} \text { Tabel }\end{array}$ & 228,580 & 208,408 & 192,265 & \multirow{2}{*}{ Good fit } \\
\hline Significance Probability $(\mathrm{p})$ & $\geq 0,05$ & 0,243 & 0,501 & Good fit \\
\hline GFI & $\geq 0,90$ or approaching 1 & 0,921 & 0,926 & Good fit \\
\hline RMSEA & $\leq 0,080$ or 0,050 & 0,018 & 0,000 & Good fit \\
\hline TLI & $\geq 0,90$ or approaching 1 & 0,993 & 1,000 & Good fit \\
\hline AGFI & $\geq 0,90$ or approaching 1 & 0,897 & 0,903 & Good fit \\
\hline CFI & $\geq 0,90$ or approaching 1 & 0,994 & 1,000 & Good fit \\
\hline CMIN/DF & $<2,00$ & 1,069 & 0,996 & Good fit \\
\hline
\end{tabular}

Source: Results of data processing (2019)

Absolute Fit Indices test that compares directly the sample covariance matrix with estimates. One of them is the chi-square test (x2). After modifying the model, the calculated chi-square value of 192,265<chi-square table 228,580 . This shows that the model is valid because the sample covariance matrix is the same as the estimation matrix. By looking at the significance level of $0,000<0.05$ it means that the model becomes fit.

If one of the Goodness of Fit (GoF) criteria has been met then the model can already be considered feasible (Widarjono, 2015). According Hair et al, 2010 said that the use of 4-5 GoF was considered to be sufficient to assess the feasibility of a model, with the condition that each criterion from GoF namely Absolute Fit Indices, Incremental Fit Indices and Parsimony Fit Indices represented (Haryono, 2017). Based on the table above, it can be seen the results of goodness of fit obtained that there are all criteria that show the results of good fit. 


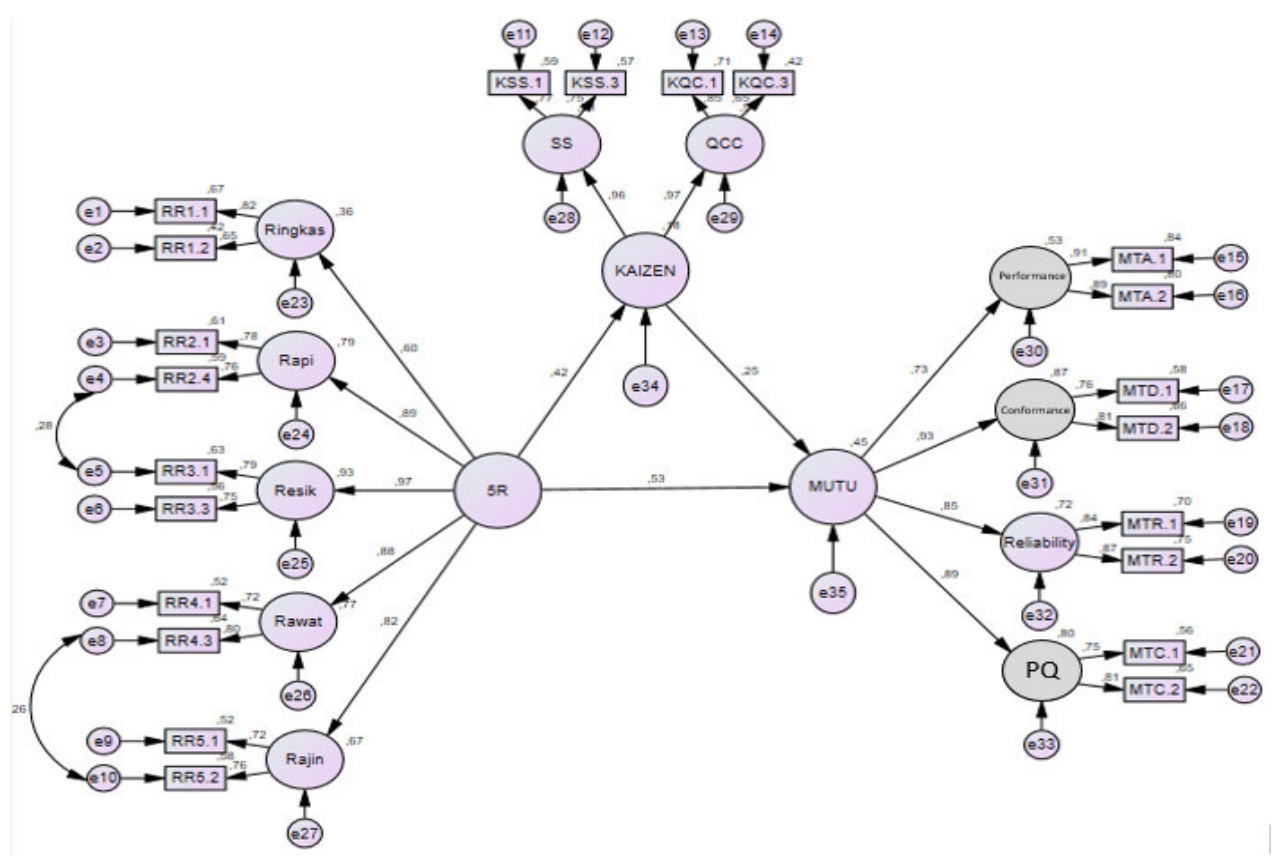

Figure 2. AMOS-Modified output model

\section{Hypothesis testing}

In the complete structural model that has been modified and declared fit, then the hypothesis test is performed. The results of the hypothesis test are summarized in the table below.

\begin{tabular}{|c|c|c|c|c|c|c|c|}
\hline \multicolumn{3}{|c|}{ Description } & Estimate & S.E. & C.R. & $\mathrm{P}$ & Label \\
\hline KAIZEN & $<---$ & $5 \mathrm{~S}$ & ,422 &, 150 & 4,417 & **** & par_1 \\
\hline Quality & $<---$ & KAIZEN & 246 & ,076 & 3,057 & $* * *$ & par_2 \\
\hline Quality & $<---$ & $5 \mathrm{~S}$ &, 529 & , 155 & 5,053 & $* * *$ & par_3 \\
\hline SS & $<---$ & KAIZEN & ,963 & 136 & 6,774 & $* * *$ & par_4 \\
\hline QCC & $<---$ & KAIZEN & ,967 & & & & \\
\hline Sort & $<---$ & $5 \mathrm{~S}$ & 603 & & & & \\
\hline Set in order & $<---$ & $5 \mathrm{~S}$ & ,966 & ,219 & 6,710 & $* * *$ & par_5 \\
\hline Shine & $<---$ & $5 \mathrm{~S}$ & ,878 & ,223 & 6,784 & $* * *$ & par_6 \\
\hline Standardize & $<---$ & $5 \mathrm{~S}$ & ,818 & ,200 & 6,298 & $* * *$ & par 7 \\
\hline Sustain & $<---$ & $5 \mathrm{~S}$ & ,932 & , 195 & 6,057 & $* * *$ & par_8 \\
\hline Conformance & $<---$ & Quality & 847 & & & & \\
\hline Reliability & $<---$ & Quality & 894 & ,113 & 9,014 & $* * *$ & par_9 \\
\hline Perceived Quality & $<---$ & Quality & ,731 & ,111 & 8,464 & $* * *$ & par_10 \\
\hline Performance & $<---$ & Quality &, 820 & 101 & 9,107 & $* * *$ & par_11 \\
\hline RR1.1 & $<---$ & Sort & 649 & & & & \\
\hline RR1.2 & $<---$ & Sort & ,780 & , 128 & 6,065 & $* * *$ & par_12 \\
\hline RR2.1 & $<---$ & Set in Order & ,765 & & & & \\
\hline RR2.4 & $<---$ & Set in Order & ,794 & ,096 & 10,160 & $* * *$ & par_13 \\
\hline RR3.1 & $<---$ & Shine & ,745 & & & & \\
\hline RR3.3 & $<---$ & Shine & ,724 & ,091 & 10,856 & $* * *$ & par_14 \\
\hline RR4.1 & $<---$ & Standardize & 799 & & & & \\
\hline RR4.3 & $<---$ & Standardize & ,722 & ,118 & 9,786 & $* * *$ & par_15 \\
\hline RR5.1 & $<---$ & Sustain & ,762 & & & & \\
\hline RR5.2 & $<---$ & Sustain & ,765 & , 122 & 8,636 & $* * *$ & par 16 \\
\hline KSS.1 & $<---$ & SS & 755 & & & & \\
\hline KSS.3 & $<---$ & SS &, 845 & , 103 & 10,047 & $* * *$ & par_17 \\
\hline
\end{tabular}




\begin{tabular}{|lrl|rrrrr|}
\hline \multicolumn{2}{|c|}{ Description } & Estimate & S.E. & C.R. & P & Label \\
\hline KQC.1 & $<---$ & QCC &, 647 & & & & \\
KQC.3 & $<---$ & QCC &, 914 &, 088 & 8,917 & $* * *$ & par_18 \\
MTA.1 & $<---$ & Performance &, 894 & & & & \\
MTA.2 & $<---$ & Performance &, 760 &, 067 & 14,857 & $* * *$ & par_19 \\
MTD.1 & $<---$ & Conformance &, 813 & & & & \\
MTD.2 & $<---$ & Conformance &, 836 &, 096 & 11,167 & $* * *$ & par_20 \\
MTR.1 & $<---$ & Reliability &, 868 & & & & \\
MTR.2 & $<---$ & Reliability &, 746 &, 077 & 13,137 & $* * *$ & par_21 \\
MTC.1 1 & $<---$ & Perceived Quality &, 806 & & & & \\
MTC.2 & $<---$ & Perceived Quality &, 966 &, 101 & 10,391 & $* * *$ & par_22 \\
\hline
\end{tabular}

Source: Results of data processing (2019)

Hypothesis testing from this study the most dominant estimation value is the implementation of $5 \mathrm{~S}$ with a value of 0.529 , which means the application of $5 \mathrm{R}$ has more effect to improve Quality compared to Kaizen variables. Based on the above table, the following hypothesis test results are obtained:

Hypothesis 1: Implementation of 5S has a positive effect on Quality

Based on data from the analysis results in the table 6. Show that the implementation of $5 \mathrm{~S}$ has a positive effect on quality. The parameter value is estimated at 0.529 , indicating that each increase in one unit of implementation of 5S can improve Quality by 0.529 . Obtained the indicators that most influence Quality, namely "Productivity level" with the Performance dimension with a loading factor of 0.914 so that it becomes a major consideration for companies to improve Quality. This is consistent with previous research that $5 \mathrm{~S}$ provides improved performance (Rojasra, P. M et al, 2013) and reduced operating time for machine replacement (Ab Rahman et al, 2010)

Hypothesis 2: Implementation 5S has a positive effect on Kaizen

Based on data from the analysis results in the table 6 . Shows that the implementation of $5 \mathrm{~S}$ has a positive effect on Kaizen. The estimated parameter value of 0.422 shows that each increase of one unit of implementation of $5 \mathrm{~S}$ can increase Kaizen by 0.422 . Previous studies have also shown that the $5 \mathrm{~S}$ provides a reduced operating time for engine replacement (Ab Rahman et al, 2010). While Kaizen also has a positive effect on quality with a parameter value of 0.246 . So that the indirect effect of the implementation of $5 \mathrm{~S}$ on Quality is obtained by $0.104(0.422 \mathrm{x}$ 0.246). This explains that the application of the $5 \mathrm{~S}$ has a positive effect on Quality through Kaizen as mediation. Based on the results of the confirmatory factor analysis indicator "Identification and classification of goods (necessary and not required)" with a loading factor of 0.820 on the Sort dimension which has the greatest coefficient value so it becomes a major consideration for companies to improve Kaizen. In accordance with research from (Arash Ghodrati et al, 2012) which states that 5S provides efficiency benefits for organizations.

Hypothesis 3: Kaizen has a positive effect on Quality

Based on data from the analysis results in the table 6. Shows that Kaizen has a positive effect on Quality. The estimated parameter value of 0.246 indicates that each increase of one unit of Kaizen can improve Quality by 0.246. In accordance with some previous researches that Kaizen will provide a problem solving method (C.P.Carvalho et al, 2017) and can contribute in improving Quality and Performance (Rajesh Mahto et al, 2017). Based on the results of the confirmatory factor analysis indicator "The scope of internal improvement department and or section (group)" with a loading factor of 0.845 on the dimension of Quality Control Circle (QCC) has the greatest coefficient value so that it becomes a major consideration for companies to improve quality.

\section{Conclusion}

Based on the results of data analysis, this study can be concluded as follows:

1. The implementation of $5 \mathrm{~S}$ has a significant and positive effect on quality and Kaizen.

2. Kaizen has a significant and positive effect on quality.

3. There is a significant and positive mediating effect of the Kaizen on the $5 \mathrm{~S}$ relationship to Quality.

\section{References}

Ab Rahman, M. N., Khamis, N. K., Mohd Zain, R., Md Deros, B., \& Wan Mahmood, W. H. 2010. Implementation of $5 \mathrm{~S}$ practices in the manufacturing companies: A case study. American Journal of Applied Sciences, 7(8), 1182-1189.

C.P.Carvalho, L.W.N.Gonçalves \& M.B.Silva, 2017, Kaizen and 5S as Lean Manufacturing Tools for Discreat Production Systems: A Study of the Feasibility in a Textile Company, International Journal of Research Studies in Science, Engineering and Technology, 4 (7), 1-12.

Fandy Tjiptono. 2005. Pemasaran Jasa, $1^{\text {st }}$ edition, Bayu Media Publishing, Malang.

Ferdinand, Augusty. 2006. Structural Equation Modeling dalam Penelitian Manajemen: Aplikasi Model-model 
Rumit dalam penelitian untuk Thesis Magister \& Desertasi , Doktor, Badan Penerbit Universitas Diponegoro, Semarang.

Ghodrati, A., \& Zulkifli, N. 2013. The Impact of 5S Implementation on Industrial Organizations' Performance. International journal of business and management invention, 2(3), 43-49.

Ghozali, I. 2016. Structural Equation Modeling: Teori, Konsep, dan Aplikasi.Semarang: Badan Penerbit Universitas Diponegoro, Semarang.

Haryono, S. 2017. Metode SEM Untuk Penelitian Manajemen AMOS Lisrel PLS. Luxima Metro Media. $1^{\text {st }}$ edition : Februari 2017, page 371.

Ho, S. 2008. TQM and Change Management Via 5-S, Retrieved from http:/www.saferpark.com,

Imai, Masaaki. 2008. Genba Kaizen, PPM, Jakarta.

Mawih and Niken Sulistyowati, 2019, The Influence of Total Quality Management and Occupational Health and Safety on Operational Performance at PT. BS, International Journal of Latest Research in Engineering and Management, page 01-05.

Osada, T. 2000. Sikap Kerja 5S, PPM, Jakarta.

Rajesh Mahto \& Prakash Kumar, 2017. Kaizen for Quality and Productivity Improvement in Manufacturing Industry, International Journal of Engineering Sciences \& Research, 19-32.

Rojasra, P. M., \& Qureshi, M. N. 2013. Performance improvement through 5S in small scale industry: a case study. International Journal of Modern Engineering Research, 3 (3), 1654-1660.

Widarjono, Agus. Ph. D. 2015. Statistika Terapan Edisi Pertama, UPP STIM YKPN, Yogyakarta. 